Journal of Southeast Asian

\title{
Heritage Language Maintenance and Use among 1.5 Generation Khmer College Students
}

Ravy S. Lao

University of California, Santa Barbara, rlao@education.ucsb.edu

Jin Sook Lee

University of California, Santa Barbara, jslee@education.ucsb.edu

Follow this and additional works at: https://docs.lib.purdue.edu/jsaaea

Part of the Asian American Studies Commons, Education Commons, and the Linguistics Commons

\section{Recommended Citation}

Lao, Ravy S. and Lee, Jin Sook (2009) "Heritage Language Maintenance and Use among 1.5 Generation Khmer College Students," Journal of Southeast Asian American Education and Advancement. Vol. 4 : Iss. 1, Article 3.

DOI: $10.7771 / 2153-8999.1094$

Available at: https://docs.lib.purdue.edu/jsaaea/vol4/iss1/3

This document has been made available through Purdue e-Pubs, a service of the Purdue University Libraries. Please contact epubs@purdue.edu for additional information.

This is an Open Access journal. This means that it uses a funding model that does not charge readers or their institutions for access. Readers may freely read, download, copy, distribute, print, search, or link to the full texts of articles. This journal is covered under the CC BY-NC-ND license. 


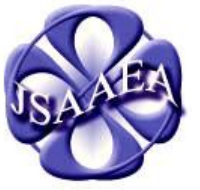

Volume 4 (2009)
Journal of Southeast $A$ sian $A$ merican

Education \& Advancement

WWW.JSAAEA.org
A peer-reviewed

scholarly journal

published by the

National Association

for the Education \&

Advancement of

Cambodian, Laotian,

and Vietnamese

Americans (NAFEA)

\title{
Heritage Language Maintenance and Use among 1.5 Generation Khmer ${ }^{1}$ College Students
}

\author{
Ravy S. Lao and Jin Sook Lee \\ University of California, Santa Barbara
}

\begin{abstract}
Most studies of heritage language maintenance have reported a steep attrition in heritage language use among the 1.5 and $2^{\text {nd }}$ generation children of immigrants, in particular among East Asian groups. However, not much is known about the role of heritage languages and the patterns of language maintenance within refugee communities. This study focuses on heritage language use and maintenance among 1.5 generation Khmer college students. The findings show that Khmer students report a high frequency of heritage language use within the home with their parents as well as outside of the home with their co-ethnic peers. The data reveal that oral proficiency in Khmer is significantly more developed than literacy skills and is a necessity for bridging communication with parents and participating in co-ethnic peer social networks. The results of the study also indicate that these students' development of English oral and literacy skills were significantly higher than their heritage language skills suggesting a similar trajectory of language loss similar to other immigrant groups, but perhaps at a slower rate.
\end{abstract}

"I think language has a lot to do with it [knowing one's roots] because if you know the language, you immerse yourself in that culture ... its past, its future, its present."

—Soudany (21-year-old Khmer college student)

For Soudany, a Khmer living in the United States, and many others like her, speaking the heritage language (HL) is the key through which cultural roots can be discovered and maintained. However, the maintenance of the heritage language has been especially challenging for children of immigrants and refugees in the United States. Historically, language minority groups have experienced a three-generational language shift resulting in monolingual English speakers by the $3^{\text {rd }}$ generation (Veltman, 1988). Moreover, recent studies have documented even

\footnotetext{
(c)

SORERIIGHISRESERVEDReaders are free to copy, display, and distribute this article, as long as the work is attributed to the author(s) and the Journal of Southeast Asian American Education \& Advancement, it is distributed for non-commercial purposes only, and no alteration or transformation is made in the work. More details of this Creative Commons license are available at http://creativecommons.org/licenses/by-nc-nd/3.0/. All other uses must be approved by the author(s) or JSAAEA.
} 
faster rates of heritage language loss among the 1.5 and $2^{\text {nd }}$ generation children of immigrants, particularly in East Asian groups, where the shift to English is completed by the $2^{\text {nd }}$ generation (Wong-Fillmore, 2000; López, 1996). Although there have been several studies conducted on heritage language maintenance in East Asian immigrant groups (Cho, 2000; Lee, 2002; Shin, 2005; Tse, 1998; Wong-Fillmore, 2000), research on Southeast Asian children's heritage language, with the exception of a few studies, is scarce (Portes \& Rumbaut, 2001; Wright, 2003, 2004). A closer examination of Southeast Asian children's heritage language experiences is necessary not only because of the importance of understanding the central ways in which the heritage language plays a role in developing relationships within families and co-ethnic communities, but also because there are likely to be differences in heritage language maintenance patterns between immigrant and refugee groups due to the contrasts in the origins and motivations for immigration, the sociopolitical contexts of immigration, as well as cultural practices and norms ${ }^{2}$ (Ogbu, 1987; Ogbu \& Simons, 1998).

In the current educational climate, one of the top priorities is in improving English language development among children of immigrants and refugees. This study examines the HL maintenance patterns and use among the 1.5 generation Khmer college students, who have successfully navigated the educational pathways to be able to enter college. This population offers a lens to understanding the role of the heritage language in the lives of linguistic minority youth who have been successful in acquiring English. In this study, the 1.5 generation is a broad category referring to children of first generation refugees, who were born outside of the United States. We focus on the 1.5 generation in this study because this is the population of students who are amongst the first wave of Khmer refugee children to enter higher educational institutions in the United States. Although some scholars make finer distinctions such as the 1.25 or the 1.75 generation to capture the differences experienced by youths who arrive to the host country at different life phases, ${ }^{3}$ for the purposes of this study, we group these individuals as the 1.5 generation to distinguish them from the $2^{\text {nd }}$ generation born in the United States. Furthermore, the majority of our research participants were of Khmer decent; however, some individuals identified themselves as Chinese Khmer ${ }^{4}$. To better understand language use and heritage language maintenance patterns, this study addresses the following questions:

1) What are the patterns of language use in the home and outside of the home among 1.5 generation Khmer college students?

2) What are the self-perceived levels of oral and literacy skills in the heritage language and English among 1.5 generation Khmer college students?

3) Do (a) attendance of HL school, (b) language practices, and (c) perceived parental and self attitudes toward the HL affect the HL proficiency and preferences for language use among 1.5 generation Khmer college students?

\section{The Role of Heritage Language in the Lives of Immigrant Children}

Prior research has shown that heritage language affects the person, family, community and educational spheres of ethnic minority children's lives in various ways (Lee \& Suarez, in press). Studies have found that proficiency in the HL supports maintenance and enhancement of family relationships and ties with members of the ethnic community (Cho, 2000; Luo \& Wiseman, 2000; Portes \& Hao, 2002). For instance, children who are fluent in their HL are less likely to experience frequent conflicts with parents than children of immigrants who only speak English 
(Portes \& Hao, 2002). This is not surprising given that most first generation immigrant and refugee parents do not acquire English proficiency at the rate that their children do. Without a common language, tensions and miscommunication within the family are inevitable. In another study, Tannenbaum and Howie (2002) examined upper elementary school-aged Chinese immigrant children living in Australia to determine the role of heritage language in immigrant families, specifically the connection between parent-child relationship and the children's heritage language maintenance. They found the children's use of their heritage language was connected to how they perceived the closeness of their family; that is, higher proficiency in the HL predicted perceptions of stronger family cohesion. Moreover, in a study by Cho (2000) on generation 1.5 adults of Korean descent, she found that those who had maintained their heritage language competence experienced better relationships with other heritage language speakers. The maintenance of their home language by immigrant children was critical because it enabled them to gain access to their parental guidance and social capital in the community. The need to have a common means of communication is particularly important for Khmer children because they have been found to experience high levels of acculturative stress resulting from parent-children conflicts at home (Ong, 2004; Um, 1999).

Furthermore, other studies have found that immigrant children who can speak their HL have a stronger sense of identity, higher self-esteem, and self-determination (Cho, Cho, \& Tse, 1997; Hinton, 1999; Phinney, Romero, Nava, \& Huang, 2001; Stalikas \& Gavaki, 1995). There has been a great public concern that immigrants who maintain ties to their ethnic language and culture are resisting assimilation into the host culture (Crawford, 1999); however, on the contrary, research has found that immigrant individuals who can speak their HL are more connected with both the culture of their host country as well as their ethnic culture (Feuerverger, 1991; Imbens-Bailey, 1996; Lee, 2002; Tse, 1998). For instance, Fuerverger (1991) found that bilinguals living in Canada felt a stronger connection to both their home culture and that of Canadian culture, resulting in high levels of biculturalism. Imbens-Bailey (1996) reported similar findings for bilingual individuals living in the United States. In other words, individuals who had a stronger sense of their ethnic identity also had stronger identification with their host countries, indicating a preference for a bicultural identity.

In terms of immigrant students' academic spheres, examining Vietnamese immigrant children in New Orleans, Bankston and Zhou (1995) found that literacy in Vietnamese is positively related to academic achievement in English among this group. A study focusing on Spanish speaking children of immigrants also found correlations between reading and writing in Spanish and achievement scores and GPA (grade point average) in English (García-Vázquez, Vázquez, López, \& Ward, 1997). In essence, García-Vásquez and her colleagues reported that students who maintained their HL, in the form of additive bilingualism, experienced greater academic outcomes on standardized tests in comparison to their English monolingual counterparts. The positive relationship between heritage language maintenance and academic achievement makes sense in that children who have high heritage language proficiency are perhaps also the ones that have high self-esteem and are able to develop stronger relationships with parents and other ethnic community members, which are all necessary conditions for positive academic experiences.

However, despite studies showing the positive relationship between HL maintenance and academic outcomes among linguistic minority students as mentioned above, we commonly witness the negative consequences of schools failing to utilize students' heritage language to assist them in their schooling. Following a group of Khmer students who attended a school 
district in Southern California that failed to properly comply with state and federal policies in assisting ELL students, Wright (2003, 2004) documented how the lack of home language support had negative consequences on these students in the forms of heritage language loss, low academic English skills, and negative effects on their self-identity and family communication. Scholars have widely argued for the educational benefits of tapping into and utilizing students' funds of knowledge, which are resources, skills and knowledge bases that students bring from their home culture such as their heritage language (Moll, Amanti, Neff, \& Gonzalez, 1992). With high rates of low academic achievement among Khmer students (Reeves \& Bennett, 2004; Rumbaut \& Ima, 1988), it is of urgency to explore multiple pathways that can improve Khmer students' educational outcomes. Given the positive benefits that HL proficiency is likely to bring immigrant children in their personal, social, and educational spheres (Lee \& Suarez, in press), HL development and maintenance may be one mechanism through which the overall well-being of Khmer immigrant children can be improved. Greater resources and public support are needed, for example, to assist in the development of Khmer heritage language schools and bilingual programs, particularly in areas where there is a high concentration of Khmer students. One positive model is a current program, supported by three public organizations in a local community in Southern California, which offers free Khmer literacy lessons on a weekly basis at a local public library (Lao, 2009). The significance of this program lies in the fact that it is organized and supported through a collaboration between Khmer community members and public agencies that have gained an awareness and appreciation for the need and value of heritage language support for their ethnic community members.

\section{Participants}

\section{Methods}

The data for the present study come from a larger study that was conducted in 2001-2002 on Khmer Americans' language and educational experiences. The selection criteria for participants were that they must be: (1) 18 years or older and (2) 1.5 generation Khmer immigrants (i.e., born outside the United States) and (3) currently, enrolled in a four-year university or college. After the initial selection screening, 93 participants of whom 47 were males and 46 females were included in this study. The ages of the informants ranged from 18 to 36 years, with a mean age of 22.6. In this 1.5 generation Khmer college-student sample, the majority $(65.6 \%, \mathrm{n}=61)$ of them arrived in the United States before the age of 5, while only $34.4 \%(n=32)$ arrived after the age of 5. Thus, most of the informants started their formal education in kindergarten in the United States. They indicated that their family immigrated to the United States between 1976 and 1990, but the majority $(78 \%, n=73)$ of the informants reported to have immigrated to the United States between 1980 and 1985 .

Interestingly, 74\% $(\mathrm{n}=69)$ of the participants reported they came from a two-parent household, while $26 \%(\mathrm{n}=24)$ indicated they lived with a single parent. The high number of twoparent households runs counter to other studies that found most Khmer children to grow up in non-intact families (Ong, 2004; Rumbaut \& Ima, 1988). One reason for this finding may be that the participants were recruited on college campuses. Research has shown that children from single-parent households do not do as well in school than those from two-parent households (Sun, 2001). Thus, it is likely that having a two-parent household increased the students' chances to attend college. 
In terms of ethnic identity, the majority, 74 respondents $(79.6 \%)$ identified themselves as Khmer American and 19 respondents (20.4\%) identified themselves as Chinese-Khmer American. As for heritage language classes, a little over half of the respondents $(54.8 \%, \mathrm{n}=51)$ stated that they did not attend any heritage language classes, while $45.2 \%(n=42)$ stated that they did. However, among those who attended heritage language classes, $47.6 \%(n=20)$ attended the program for less than one year and 52.4\% $(n=22)$ reported attending for 2 or more years. The heritage language classes that were available to the informants were generally offered by community volunteers on the weekends in local Buddhist temples (wats) or Khmer community organizations.

\section{Instruments}

The questionnaire, consisting of 59 items, was grouped into four main sections: personal background; language background; language input; and culture and identity. The questionnaire was provided in English only, because the assumption based on the selection criteria was that the informants were English proficient. The personal background section includes questions about age, gender, place of birth, and age at time of immigration to the United States. The section on language background elicits self-assessments about language proficiency in English and Khmer (e.g., "How well would you say you are able to speak Khmer?") and language use patterns at home and outside of the home (e.g., "To whom do you speak English? To whom do you speak Khmer?"). There were 28 items that asked about heritage language class attendance, attitudes toward the heritage language (e.g., "How would you rate the worth of knowing how to read and write Khmer in the U.S.?"), and living environment (e.g., "Please describe your neighbors when you were growing up"). Finally, the culture and identity section includes questions dealing with ethnic identification (e.g., "How do you identify, that is, what do you call yourself?") and cultural preferences for social conducts.

In the language input section of the survey, participants were asked to rate their perceptions of their oral (speaking and listening) and literacy (reading and writing) proficiency in three languages: Khmer, Chinese and English. A total of 12 questions, on a Likert scale (3=very well; 2=well; $1=$ not well; and $0=$ not at all), were constructed for this section. Although the majority of the informants in this study indicated Khmer as their heritage language, some informants (5 of the 93) reported Chinese to be their heritage language. Whether it was Khmer or Chinese, both were treated as the heritage language for the research participants. These assessments were based on self-reported data.

\section{Procedures}

The surveys were distributed through a paper and pencil questionnaire and an on-line survey. First, Khmer/Cambodian student associations on four university/college campuses located in Southern California were contacted to request participation in the study. A total of 67 surveys were hand-distributed and completed in the presence of the researcher. There were no financial incentives offered to participants.

Secondly, in order to reach a larger 1.5 generation Khmer immigrant population, the

same questionnaire was also posted on the Internet at (http://www.angelfire.com/ yt2/surveys/index.html) and then linked to the Khmer Connection website (http://www. khmer.com). Khmer Connection is an international website where mostly young Khmer adults 
living in diaspora engage in on-line communication with co-ethnic group members. The survey remained online for three months. In this period of time, a total of 57 surveys were completed by participants. However, only 26 out of the 57 were included in the study because some of the informants did not meet the three selection criteria mentioned above.

Of the survey informants that were recruited from the four campuses, volunteers were recruited to be interviewed about their heritage language maintenance and use experiences. The interview provided a more in-depth explanation of their experiences that the survey instrument was not able to capture. A total six informants were interviewed. With the exception of one woman who identified herself as Chinese Khmer that spoke both Khmer and Teochiu ${ }^{5}$ (or Chowjow in Mandarin) as a home language, the rest identified themselves as Khmer and spoke only Khmer as their home language. Consistent with the demographics reported on the questionnaires, the majority of the interviewees arrived in the United States before school age. With the exception of one informant, the majority of the interviewees were born in refugee camps. Although their place of birth (whether it was in a refugee camp or in their heritage country) may have a difference in their attachment or desire to connect with their heritage language, our survey results showed that there were no significant differences in the perceived HL proficiency levels between these two groups. Perhaps the reason may be due to the fact that most of the informants in our sample came to the United States at such an early age. Hence, they may not have distinct memories of their earlier experiences prior to their arrival in the United States. Table 1 shows the profile of the six interviewees.

The interviews were conducted in English and the protocol consisted of open-ended questions relating to language and educational backgrounds, cultural values and identity

(e.g., "What was your experience in school like while growing up?"; "When you and your parents talk about Khmer culture, what are some of the things that are brought up?"; and "What do you considered your ethnic identity to be?"). Each interview ranged from two hours to two and a half hours and was audio and video-recorded.

\section{Analysis}

Means and frequencies of the informants' Likert ratings were calculated to assess language proficiency and language use patterns. Furthermore, the means of informants' responses were also used to group the informants into different categories such as low, neutral, and high language attitudes to perform relevant statistical analyses. Chi-squares, $t$-tests, and one-way analysis of variance were conducted to examine if there were any significant differences between English and HL proficiency levels and oral and literacy proficiency in relation to heritage language class attendance, birthplace, language use, and gender. The effect sizes were also calculated to assess the strength of the relationship between the two variables being tested.

The interview data were first transcribed and coded for themes that related to the survey findings. The responses of the informants are presented to provide a deeper understanding of the statistical patterns found in the survey data. 
Table 1: Profile of the Six Interviewees

\begin{tabular}{lllllll}
\hline Name* & Gender & $\begin{array}{l}\text { Age at Time } \\
\text { of Interview } \\
\text { (in yrs.) }\end{array}$ & $\begin{array}{l}\text { Age Arrived } \\
\text { in U.S. } \\
\text { (in yrs.) }\end{array}$ & Birthplace & $\begin{array}{l}\text { Length of } \\
\text { U.S. Residency } \\
\text { (in yrs.) }\end{array}$ & $\begin{array}{l}\text { Year Family } \\
\text { Arrived in } \\
\text { U.S. }\end{array}$ \\
Chhaya & M & 21 & 1 & Thailand & 21 & 1981 \\
Lena & F & 21 & 2 & Thailand & 20 & 1982 \\
Samnang & M & 21 & 3 & Thailand & 19 & 1983 \\
Sochinda & F & 22 & 5 & Thailand & 17 & 1985 \\
Soudany & F & 20 & 7 & Cambodia & 13 & 1988 \\
Thida & F & 20 & 3 & Thailand & 18 & 1984 \\
\hline
\end{tabular}

*All names are pseudonyms to ensure anonymity.

\section{Results and Discussion}

\section{Language Proficiency}

In order to examine how the informants perceived their language skills, the informants were asked to self-rate their proficiency levels in both oral and literacy skills in English and their HL on a Likert scale from 0 (not at all) to 3 (very well). Although there has been much criticism about self-reported language assessments, research has shown that if there are no external benefits or consequences associated with language proficiency self-assessments, self-ratings correlate highly with standardized proficiency measures (Oskarsson, 1978; 1984; Oscarson, 1989; LeBlanc \& Painchaud, 1985). Thus, for the purposes of this study, self-reported perceptions of language skills were deemed to be sufficient.

As shown in Table 2, not surprisingly, the means of the 1.5 generation Khmers' selfrating for English language proficiency were higher than their HL, particularly in their literacy skills.

Table 2. HL and English Proficiency Self-Assessment

\begin{tabular}{llll}
\hline Heritage Language & Mean (SD) & English & Mean (SD) \\
\hline Speaking and Listening & $2.29(.54)$ & Speaking and Listening & $2.80(.38)$ \\
Reading and Writing & $0.69(.89)$ & Reading and Writing & $2.74(.39)$ \\
\hline Scale: 3 (very well); 2 (well); 1 (not well); 0 (not at all) & &
\end{tabular}

To ascertain whether there is a statistically significant difference between the Khmer students' English and their HL proficiency, $t$-test analyses were performed. In terms of overall proficiency (speaking, listening, reading and writing skills), the results confirmed that the informants' English is in fact significantly higher than their HL skills $[t(92)=-8.41, p=.00, d=-0.87]$. The 
large effect size indicates a significant difference in the proficiency levels of English and HL. Moreover, the negative correlation shows that the higher the English proficiency, the lower the HL proficiency, suggesting a subtractive bilingualism trajectory, where as English becomes more developed the heritage language will weaken. This pattern seems to be more representative of literacy skills than for oral skills.

To examine whether there are specific language skills that are more developed than others, further $t$-tests were conducted to compare the perceptions of language skills in English and the HL. The results showed that there is a significant difference between reading and writing proficiency in English and the HL $[t(92)=-19.24, p<.001, d=-1.99]$, but not in their oral skills. These students rated their abilities in reading and writing in English as "very well," but in contrast, they rated their heritage language literacy skills to be "very low." However, this difference between the informants' English and HL literacy skills is not surprising given that most of the informants have only received formal education in English. Interestingly, the interviews also revealed a common experience across the informants in that their families tended to place more priority in the learning of English. For example, Lena stated that she was taught the English alphabet in the home, but was not taught how to write in Khmer.

My dad taught us English so that we could go to pre-school like a year later. My dad taught us the ABCs but our Cambodian [Khmer] was better. We couldn't read or write [in Khmer], but we knew how to speak [it] well.

Thus, the results suggest that English is the dominant language in the lives of Khmer students, putting to rest the concerns that immigrant and refugee children are not faring well in their English language development.

The means also indicated generally stronger oral skills than literacy skills across the two languages. T-test results showed that there was a significant difference in the rating of their oral and literacy proficiency in English, although the effect size was not large $[t(92)=2.25, p=.027$, $d=0.23]$. Despite the fact that most of these students attended their entire schooling in the United States, they still perceived a weakness in their English literacy skills. This result supports Wright's (2004) and Souryasack and Lee's (2007) findings that showed the difficulty that Southeast students faced with academic English literacy. For instance, Wright (2004) found that most of his Khmer participants had to remain at the community college for extended years or dropped out of school because they experienced great difficulties in the courses that required extensive reading and writing in English. Similar to Wright's study, Souryasack and Lee (2007) documented a lack of opportunities for Southeast Asian immigrant students to develop strong literacy skills in middle school. Because literacy skills in English play a crucial role in education in the level of literacy skills determines school outcomes, there is a need to better understand how to improve English literacy skills for Southeast Asian students, who often fall into the longterm English language learner category. Based on the body of research that has shown positive transfer between a strong basis in one language to a second language (Cummins, 2001), it is quite possible that a stronger development of heritage language literacy skills may facilitate the development of English literacy skills.

As for the heritage language, there was a greater discrepancy between their oral and literacy skills $[t(92)=17.54, p<.001, d=1.82]$. These youths reported their perceived speaking and listening proficiency to be between "well" and "very well." However, it was a different story when it came to reading and writing in the HL; they reported that they lack these skills. This 
result aligns with findings from other heritage language learners from different immigrant groups, where there is a consistent pattern of low literacy skills in the heritage language (Luo \& Wiseman, 2000; Nguyen, Shin, \& Krashen, 2001; Valdés, 2000). The majority $(65.7 \%, \mathrm{~N}=61)$ of the informants arrived in the United States prior to receiving formal education in Khmer; so it is likely that they have had no literacy instruction in the HL unless they have experience attending a HL class. However, it is surprising that despite the fact that most of the informants arrived to the United States before school age, the informants perceived their oral proficiency in the HL to be similar to English. Thus, they seem to have achieved bilingual but not biliterate competence. In sum, the Khmer 1.5 generation seems to be on a similar, but possibly slower, language shift trajectory to those of other immigrant groups. In other words, the data show that their English proficiency is stronger than their HL proficiency and their oral skills in the HL are stronger than their HL literacy skills.

\section{Language Use Patterns}

In addition to identifying patterns in these Khmer students' proficiency in English and HL, differences in patterns of language use were also examined. The results yield both expected and unexpected findings. In the home, the informants reported that their parents predominately spoke their heritage language to them $93.5 \%$ of the time and they spoke to their parents in the HL $78.5 \%$ of the time. In the interviews, Chhaya, a male participant, echoed the predominant use of Khmer with the adults in his life. He remarked, "When I was growing up, my parents, all the adults around, they spoke Cambodian [Khmer] and I responded in Cambodian [Khmer]. All the time, it was in Cambodian [Khmer], even now, it's still Cambodian [Khmer]." Similarly, Sochinda commented,

My whole family speaks Khmer. They didn't speak English that well to speak to me in English when I was younger, even my aunts and uncles. Even right now, they still speak to me in Khmer because it's easier that way.

These two students' comments demonstrate how enduring and pervasive the use of Khmer language has been in their lives. As Sochinda's remark reveals, an impetus for her continual use of the heritage was simply due to the fact that the adults in her life had to speak Khmer to her because of their limited proficiency in English. Hence, both in the home and community, their $\mathrm{HL}$ is the dominant language of communication and a necessity.

However, when communicating with their siblings, English was the main language of communication, which is consistent with prior studies. The informants reported that $61.3 \%$ of the time they spoke English with their siblings, while they only communicated $35.5 \%$ of the time in the heritage language (see Table 3).

Table 3. Percentage of HL and English Language Use among Informants in the Home

Informants to Parents Parents to Informant Informant to Siblings
Heritage Language
$78.5 \%$
$93.5 \%$
$35.5 \%$
English
$17.2 \%$
$6.5 \%$
$61.3 \%$ 
The use of English is especially prevalent with younger siblings. Thida, a female informant, explained,

I always speak English to them [younger siblings]. I figured they're more Americanized because they have lived most of their life here. So, I speak English to them a lot. It's kind of weird to speak Khmer to your siblings when you be ${ }^{6}$ walking around. When you're in America, you be speaking Khmer to them outside the home is just awkward.

For the younger generation of Khmer youth, their ability to linguistically assimilate completely into the English speaking community is made possible by their older siblings' linguistic accommodations. They are able to learn English faster, because of the experiences and language input from their older siblings, and they do not have to be fully proficient in their heritage language, because their older siblings are able to broker the communication with Khmer speakers. This issue was brought up by Samnang who saw his role as being able to bridge the gap between his first-generation parents and second-generation younger siblings. He explained:

Lots of times, my parents would call and tell something and right after I hung up the phone, I would call the group [his younger siblings], and tell them, kind of reiterating in the language that they could understand [laughing], that kind of things. So definitely, I take that responsibility, like a bridge.

Thus, the opportunities to develop their heritage language for the younger generation is likely to be more restricted because of their limited use of the heritage language, while for the 1.5 generation, the use of the heritage language appears to be a necessity and an expectation. It is likely that the roles, attitudes, and experiences of the younger Khmer generation will be different from the $1.5 \mathrm{Khmer}$ generation discussed here. This difference warrants more research.

In addition, many bridge generations and bilingual users report a high use of mixing of the two languages (Zentella, 1997). Despite the fact that most of the informants reported having bilingual oral skills, interestingly, there was a very low percentage of usage of a mix of HL and English to the same interlocutor. Perhaps the reason for this is because most bilinguals generally code-switch or code-mix when speaking to other bilinguals with similar levels of proficiency in both languages, which is not the situation with the parents who have limited proficiency in English and their siblings who have limited proficiency in Khmer. In other words, the uses of the two languages appear to be in a fairly strict diglossic situation, where each language is reserved for certain people and certain situational domains.

Although heritage language practice has mainly been reserved for use in the home with family members, it was also surprising to find a regular use of the HL outside of the home. These Khmer students reported that they use HL (75.2\%) in the home and (78.4\%) outside of the home as well, indicating a high usage of HL. Despite the fact that they rated their English proficiency to be higher than HL language, they still reported a high frequency of interaction with co-ethnic peers and community members using the HL (see Table 4). Although we do not have the data to fully understand the range of reasons behind the use of the heritage language with other coethnic peers who also have the ability to speak English, this finding shows us that language choice is not based solely on compensatory motivations resulting from the lack of knowledge of a certain word or because of limited proficiency. We find the examination of the full range of 
social motivations for deliberate choices to use the HL socially, among individuals such as our informants who reported higher levels of competence in English, to be a very interesting topic for further investigation.

Table 4. Frequency of HL Use (in percentages) at Home and Outside of Home by Gender

\begin{tabular}{lllllll}
\multicolumn{3}{c}{} & \multicolumn{3}{c}{ Home } & \multicolumn{3}{c}{ Outside of Home } \\
\hline $\begin{array}{l}\text { Heritage Lang. } \\
\text { Use ---(Yes) }\end{array}$ & $39(41.9 \%)$ & $31(33.3 \%)$ & $75.2 \%$ & $41(44 \%)$ & $32(34.4 \%)$ & $78.4 \%$ \\
$\begin{array}{l}\text { Heritage Lang. } \\
\text { Use ---(No) }\end{array}$ & $10(10.8 \%)$ & $11(11.8 \%)$ & $24.7 \%$ & $9(9.7 \%)$ & $11(11.8 \%)$ & $21.5 \%$ \\
\hline
\end{tabular}

We were also interested in examining if there were other variables such as gender or age of arrival at the time of immigration that may have influenced HL language use patterns. Previous research has shown that females are the ones who are more likely to maintain their heritage language and pass on the HL to the next generation (Arriagada, 2005; Baral, 1979; Portes \& Hao, 2002). This leads us to expect a greater use of the HL and a higher HL proficiency level among females. However, a chi-square test showed insignificant differences in the use of the heritage language in the home and outside of the home as well as in the proficiency levels between males and females. Perhaps this pattern may change in future intergenerational transmissions of the language, but for the 1.5 generation, it appears that both males and females are equally invested in the use of HL. As mentioned earlier, an explanation for this result could be that since most of the adults in their lives were limited in their English proficiency, these youths have had to use Khmer in order to communicate with them, regardless of gender.

Another factor that was predicted to make a difference in their language use patterns is the age at the time of arrival to the United States. Prior studies have shown that the children who have had some schooling in the native country have a greater likelihood of retaining the HL and that early arrival to the host country can lead to heritage language loss (Alba, Logan, Lutz, \& Stults, 2002; Rumbaut \& Portes, 2001; Veltman, 1988). However, among the informants, there was little difference in the patterns of heritage language use in the home and outside of the home based on their age at the time of arrival to the United States. A chi-square analysis showed that the age at the time of arrival was not a significant pattern in HL use. Yet, there was a pattern for those who arrived before school age to only use the HL in the home, while those who arrived after school age to use the HL both at home and outside of the home at a greater frequency.

In sum, the opportunities to use the HL outside of the home seem to provide greater motivation and opportunities to develop their HL as well as access to more diverse domains of language use. Such opportunities are likely to be a critical factor in these individuals' ability to maintain such high levels of Khmer proficiency. This result corroborates with Luo and Wiseman's (2000) study where they found Chinese-speaking peers to be the most important factor in Chinese-American children's language maintenance. These findings also suggest that regular use of the HL both in the home and outside of the home represents the significant role of the Khmer language in these students' lives. In the home, because of the lack of English language proficiency on the part of their parents, the Khmer language is the tool that enables communication with their parents and also connects their parents to the outside Englishdominant world. Outside the home, the Khmer language keeps them connected with their coethnic peers and community members. The majority of the Khmer students who participated in 
the interviews stated that they lived in or near a Khmer community at one time or another while growing up. Sochinda explained, "Most of my life, I remember living near Khmer people. We moved several times but always in a Khmer neighborhood. So, I've pretty much lived with Khmer people." The access to a community of speakers offers heritage speakers with opportunities to use the language which in turn affords the opportunities to practice and increase one's proficiency in the language.

\section{Factors that Affect Heritage Language Proficiency}

In order to understand which factors contributed to the development of heritage language proficiency, five factors were examined to see if they influenced the level of heritage language proficiency. They were heritage language class attendance; HL use outside the home; HL use inside the home; self-language attitudes toward HL; and perceived parental attitudes ${ }^{7}$ toward HL.

T-test analyses showed that heritage language class attendance had a significant effect on the informants' ability to read and write in their heritage language $[t=3.55, p<0.001, \mathrm{~d}=1.20]$, but not on their oral ability (see Table 5). Based on the interviews, the informants indicated a wide range of experiences in terms of their attendance and quality of heritage language classes for themselves and other Khmer peers. Their attendance ranged from two months to three years; however, the majority indicated an average of about a year. Two of the interviewees attended informal classes taught by one of their parents or a neighbor and the rest enrolled in more formal classes held at the local Buddhist temple (wat). One of the limitations of this study was that the informants were not asked about the quality of the instruction and thus, we do not have the information to determine the extent to which the quality of the instruction makes a difference in the development of their HL literacy skills. However, what we do know is that participation in a heritage language program led to higher levels of HL literacy gains than non-participation. This result suggests that irrespective of the quality of the program, attendance to some degree is better than no attendance for the development of HL literacy skills.

Furthermore, heritage language use outside the home had a significant effect on informants' speaking and listening ability $[t=-4.43, p<0.00, \mathrm{~d}=3.32]$ and reading and writing ability $[t=-2.90, p<0.005, \mathrm{~d}=5.26]$. The large and positive effect sizes show that the more the HL is used outside the home, the greater the informant's oral and literacy proficiency. However, it is unclear whether it is the stronger language proficiency that leads to greater HL use outside the home or whether the willingness to take up HL use outside the home is leading to greater proficiency in the HL. This result may also be confounded with the age at time of arrival variable. We reported earlier that those individuals who arrived to the United States after school age reported using more HL outside the home. However, we suspect that the age at time of arrival may only have had a minimal effect, because most of the informants arrived before school age. In addition, the length of U.S residency and the number of years in the U.S. education system are likely to have overshadowed most of the effects of schooling in the native country. What was most interesting was that HL use in the home with parents and siblings did not have any effect on HL proficiency (see Table 5), putting to question common assumptions that HL can be developed solely in the home.

The effects of language attitudes on the informants' heritage language proficiency were tested using a one-way ANOVA. Based on the means and frequencies of the informants' ratings of their HL attitudes, the informants were grouped into three categories: low/negative attitudes, neutral attitudes, and high/positive attitudes. A statistically significant difference was 
Table 5. Attendance of HL School and HL Use Outside of Home by HL Language Proficiency

\begin{tabular}{lll}
\hline & HL Speaking/Listening & HL Reading/Writing \\
\hline & Mean (SD) & Mean (SD) \\
Attendance of HL School & $2.31(.51)$ & $1.04(.87)$ \\
No attendance of HL School & $2.26(.58)$ & $0.41(.82)$ \\
HL use outside of home & $2.40(.56)$ & $2.00(.38)$ \\
HL use in home & $1.86(.48)$ & $0.83(.95)$ \\
\hline
\end{tabular}

Scale: 3 (very well); 2 (well); 1 (not well); 0 (not at all)

found for informants with differing attitudes in their heritage language literacy proficiency [F (2, $90)=7.24, p<.001]$. Table 6 shows the mean and standard deviation comparing informants' attitudes, and Table 7 presents the variance summary.

Table 6. Means and Standard Deviation Comparing Informants' Attitudes

\begin{tabular}{llll}
\hline $\begin{array}{l}\text { Informants' Attitudes } \\
\text { of Importance } \\
\text { of their Heritage Language }\end{array}$ & $\mathbf{N}$ & $\mathrm{M}(\mathrm{SD})$ & $\mathrm{M}(\mathrm{SD})$ \\
$\begin{array}{l}\text { Low Value } \\
\text { Neutral }\end{array}$ & 35 & $2.26(.46)$ & $0.39(.72)$ \\
High Value & 26 & $2.23(.67)$ & $0.56(.90)$ \\
Total & 32 & $2.36(.53)$ & $1.14(.91)$ \\
\hline
\end{tabular}

Not surprisingly, those that had more positive self-attitudes toward the HL significantly had greater literacy proficiency in the HL, but their attitudes did not have an effect on oral proficiency. A post-hoc Tukey test showed that there is a significant difference between those that have negative $(p<.001)$ or neutral $(p<.05)$ attitudes toward the heritage language versus those with positive attitudes toward the heritage language. Furthermore, the results revealed that

Table 7. One-Way Analysis of Variance Summary Table Comparing Informants' Attitudes Toward Heritage Language

\begin{tabular}{llllll}
\hline Source & df & SS & MS & F & $p$ \\
\hline $\begin{array}{l}\text { Reading and Writing } \\
\text { Between groups }\end{array}$ & 2 & & & & \\
Within groups & 90 & 10.19 & 5.10 & 7.24 & .001 \\
Total & 92 & 63.32 & .70 & & \\
& & 73.52 & & & \\
Speaking and Listening & & & & .47 & .627 \\
Between groups & 2 & .28 & .14 & & \\
Within groups & 90 & 26.92 & .30 & & \\
Total & 92 & 27.20 & & &
\end{tabular}


literacy skills are better developed among those who have positive attitudes toward the language. This makes sense because the individuals with more favorable attitudes are likely to be the ones that seek out opportunities to speak the language outside the home, and that make a conscious effort to attend heritage language classes. However, language attitudes did not affect the HL oral proficiency levels among the informants. Most Khmer 1.5 generation students in the sample indicated a strong level of oral proficiency in their HL. It appears that for these Khmer students speaking Khmer at home is not a choice, but a necessity for them as a means to communicate with their parents who are typically non-English speakers.

In terms of perceived parental attitudes, previous research has placed much emphasis on the role and attitudes of parents in the maintenance and use of heritage language among children (Shin, 2005). However, in this study, perceived parental attitudes toward the heritage language were not significantly correlated with either speaking and listening or reading and writing proficiency in the heritage language.

Interestingly, the interviews revealed another important factor that contributed to the need and desire to maintain the heritage language. The informants stated that interest in the Khmer pop culture also helps 1.5 youth maintain their heritage language. For Thida, watching Thai and Chinese mini soap opera shows that were dubbed in Khmer helped her maintain the language, especially her listening skills. She recalled,

As a child, it [heritage language maintenance] was because I lived around a lot of Khmer people. My neighbors were Khmers and my parents spoke to me in Khmer. In middle school and high school, it was because of the movies.

Similar to Thida, Lena also attributed her Khmer maintenance to the dubbed foreign movies. She explained,

The reason I speak Khmer and the reason that I could speak Khmer is because I watched a lot of Thai and Chinese movies that spurred my interest. That was the main reason I wanted to keep the whole Cambodian [Khmer] thing [giggling] because I wanted to watch those movies. They were interesting to me.

Besides the dubbed movies, however, for other informants like Sochinda, karaoke assisted her with Khmer literacy. That is, in order to read the lyrics to sing the songs, she had to know how to read Khmer. She mentioned,

I wanted to learn how to read [in Khmer] because of karaoke. If I sing [in Khmer], I have to memorize the whole song . . . but if you listen to the music and you read them, it would be easier.

In addition to the need for Khmer as a means of communication, Khmer also serves as a means to engage with popular culture to which youth can easily relate. The appeal of the Khmer pop culture to the 1.5 generation youth is that they can see a reflection of themselves in the movies and music; for example, the characters in the movies are played by people that look like them and behave like them, which is a connection not easily made in Hollywood movies. Thus, the role of ethnic pop culture serves not only as a motivating factor and opportunity for heritage language, but it also serves as a social and bonding mechanism that warrants further study. 
In sum, many studies on heritage language have documented the difficulties and challenges that immigrant groups face in maintaining their home language across generations. For instance, although children are generally proficient in the heritage language before school, once they start school, they experience HL loss at accelerated rates (Hinton, 1999; Shin, 2005; Wong-Fillmore, 2000). In the case of the 1.5 generation Khmer young adults, if we consider only oral proficiency as representative of heritage language maintenance then for this generational cohort, they are displaying evidence of HL maintenance. Given that the majority $(65.6 \%, \mathrm{~N}=61)$ of the informants had arrived to the United States before school age and had also lived in the United States for more than 20 years at the time of study, it is surprising that they are still maintaining their heritage language at such high levels. On the other hand, if literacy skills are included in the definition of heritage language maintenance, the results show that these 1.5 Khmers are following the same HL loss patterns as other immigrant groups. However, this outcome is not surprising since again the majority of them arrived to the United States prior to receiving formal education in Khmer.

\section{Conclusion and Directions for Further Research}

This study about the 1.5 generation Khmer college students both corroborates and also extends our understanding of the heritage language maintenance process in the Khmer community. Although HL loss in this group seems to be slower in comparison to other second generation Asian ethnic groups (López, 1996), like other immigrant groups, English proficiency appears to be headed in the direction of replacing HL proficiency. Thus, active measures need to be taken to foster an additive model of dual language development to counter the subtractive model that is currently in place. Three findings from this study suggest some measures that can be taken to support additive bilingualism in the Khmer community.

First, the findings point to the potential that heritage language programs or community schools hold. Although there have been criticisms of the effectiveness of such programs (Lee, 2002), the findings suggest that heritage language classes play an important role in the development and maintenance of HL literacy skills. Thus, more research and resources should be invested in finding ways to support and improve what such programs have to offer young ethnic minority students.

Second, HL language use opportunities outside the home in the community played a critical role in the maintenance of the HL. This suggests that the HL spoken in the home alone is not enough. For informants like Sochinda and Soudany, who grew up in various Khmer communities in Southern California, they reported that access to their community helped them to maintain their HL. For Sochinda, it helped with both her verbal and literacy skills. She explained,

We probably lived there for ten years. So we were with other Cambodians [Khmers]. I think that what helped me with my Khmer, especially how to read and write a little bit. My friend's aunt was teaching [Khmer literacy] when I was in elementary [school], and I sat down and learned it.

Similarly for Soudany, living in a Khmer community helped her maintained her roots. She pointed out, 
It was very helpful being in an ethnic enclave because you kindda like learned to appreciate your roots and you learned to broaden your perspective. That is what I'm proud of ... not being one thing. I lived in a Cambodian [Khmer] place. So I knew like how to speak Cambodian [Khmer language], stuff like that. I knew the Cambodian [Khmer] ways.

Although living in communities where there is a dominant presence of co-ethnics seems to be a powerful force in supporting ethnic minorities to maintain both their HL language and culture, in reality, many ethnic minorities do not live in such communities. Pyong Gap Min (2005) points out "as economic conditions and social standing improve, a significant proportion of immigrants move to more desirable residential districts" (p. 38). This seems to be a current trend among Khmer families, who after establishing financial stability tend to move out of their ethnic enclave to suburban neighborhoods. In this era of increasing mobility among immigrant groups, we need to better understand how shifts in contexts affect identity development, language use, and cultural understandings among ethnic minorities who grow up in communities where there is a low presence of co-ethnics and also explore more creative ways in which ethnic minorities in any location can gain access to communities of speakers of the heritage language. For example, advancements in technology and the Internet can enable ethnic minorities to find alternative ways to gain access to cultural information, to maintain ties to the homeland, to use language, and to express their identities. However, in light of these advancements we also need to reconsider what heritage language maintenance entails, what resources and opportunities are involved, and what new challenges and barriers are formed in this process.

Finally, Khmer popular cultural activities can also provide support for heritage language maintenance among 1.5 generation youth. Interviewees indicated that pop culture, either in the forms of foreign movies dubbed in Khmer or karaoke produced and imported from Cambodia, had played a prominent role in their Khmer language maintenance, especially in their late teen years. Besides providing Khmer language maintenance, these popular media offer exposure to Asian cultures and customs as well as provide a medium where Asians are presented in positive ways. Making appropriate forms of ethnic media more readily available to youth, perhaps through public libraries, can also provide a supportive mechanism for heritage language maintenance.

The HL is not only a tie that connects these youth to their family, community, and traditional cultural practices, but it is also a tie that connects them to the changing trends, values, practices, and language use within Khmer communities. Thus, the dynamic nature and fluidity of the contexts in the lives of ethnic minorities present interesting opportunities for researchers to investigate different facets of heritage language maintenance and its value and roles in the lives of ethnic youth.

\section{End Notes}

${ }^{1}$ The term "Khmer" is an emic (insider) word used within the Cambodian community to refer to both its people and the language. "Cambodia or Cambodian," typically used outside the Cambodian community by the general public, is the Anglicized rendering of the French word "Cambodge," the name which the country inherited when it was under the French colonial protectorate, 1863-1954 (Owen, 2005). The $2^{\text {nd }}$ generation Khmer youths, including some of our informants, often refer to themselves as Cambodian in English to reflect the general usage in the 
larger public. In this paper, Khmer is used to refer to both the people and language to be consonant with the way in which members of the Khmer community use it. More recently, scholars like S. Megan Berthold (1999), Nancy Smith- Hefner (1990, 1993, 1999), and Shirley S. Tang (2006) have opted to use the term Khmer for similar reasons.

${ }^{2}$ Ogbu (1987) argues that the educational and social trajectories of "voluntary" immigrants, who emigrated from their native country by choice for socioeconomic reasons, are different from "involuntary" immigrants such as the Khmer, Laotian, and Vietnamese refugees, who were forced to leave their native country due to fear of persecution, because of their different sociopolitical histories and status and motivations for coming to the host country.

${ }^{3}$ First immigrant generation can be further defined according to age of arrival: 1.75 generation (ages 0-5); 1.5 generation (ages 6-12); and 1.25 generation (ages 13-17) (see Rumbaut, 2004).

${ }^{4}$ Cambodia has a long history of Chinese settlement. During the late 1960s just prior to the occupation of the Khmer Rouge regime that was responsible for massive deaths and exodus of the country's population as political refugees, they were the largest ethnic minority in Cambodia (Willmott, 1967). Some informants in this sample referred to themselves as being both Chinese and Khmer.

${ }^{5} \mathrm{~A}$ Chinese dialect that is spoken by Chinese who live in Southern China and by the majority of Chinese Khmers.

'The informants' responses are presented verbatim. Deviations from what is prescribed in English grammatical rules are noted in the speech of the informants. We understood these to be characteristic of the social English used in their local communities rather than evidence of a lack of English language proficiency.

${ }^{7}$ We use perceived parental attitudes because we only asked the informants what they think their parents' attitudes were toward the value of the heritage language. We did not interview or survey the parents directly for this study.

\section{References}

Alba, R., Logan, J., Lutz, A., \& Stults, B. (2002). Only English by the third generation? Loss and preservation of the mother tongue among the grandchildren of contemporary immigrants. Demography, 39(3), 467-484.

Arriagada, P. A. (2005, September). Family context and Spanish-language use: A study of Latino children in the United States. Social Science Quarterly, 86(3), 599-619.

Bankston, C., \& Zhou, M. (1995). Effects of minority-language literacy on the academic achievement of Vietnamese youths in New Orleans. Sociology of Education, 68(1), $1-17$.

Baral, D. (1979). Academic achievement of recent immigrants from Mexico. NABE Journal, 3(3), 1-13.

Berthold, S. M. (1999). The effects of exposure to community violence on Khmer refugee adolescents. Journal of Traumatic Stress, 12(3), 455-471.

Cho, G. (2000). The role of heritage language in social interactions and relationships: Reflections from a language minority. Bilingual Research Journal, 24(4), 369-84. 
Cho, G., Cho, K., \& Tse, L. (1997). Why ethnic minorities need to develop their heritage language: The case of Korean-Americans. Language, Culture and Curriculum, 10, 106-112.

Crawford, J. (1999). Bilingual education: History, politics, theory and practice (4 ${ }^{\text {th }}$ ed.). Los Angeles: Bilingual Education Services.

Cummins, J. (2001). Language, power and pedagogy: Bilingual children in the crossfire. Tonawanda, NY: Multilingual Matters.

Feuerverger, G. (1991). University students' perceptions of heritage language learning and ethnic identity maintenance. Canadian Modern Language Review, 47, 660-677.

García-Vázquez, E., Vázquez, L. A., López, I., \& Ward, W. (1997). Language proficiency and academic success: Relationships between proficiency in two languages and achievement among Mexican-American students. Bilingual Research Journal, 21(4), 334-347.

Hinton, L. (1999). Trading tongues: Loss of heritage languages in the United States. English Today, 15(4), 22-30.

Imbens-Bailey, A. (1996). Ancestral language acquisition: Implications for aspects of ethnic identity among Armenian American children and adolescents. Journal of Language and Social Psychology, 15(4), 422-443.

Lao, R. S. (2009, April). Charting a new path to success: Multi-agency collaboration in the establishment of a Khmer heritage language program. Paper presented at the annual meeting of the American Educational Research Association, San Diego, CA.

Lee, J. S. (2002). The Korean language in America: The role of cultural identity in heritage language learning. Language, Culture and Curriculum, 15, 117-133.

Lee, J. S., \& Suarez, D. (in press). A synthesis of the roles of heritage languages in the lives of immigrant children. In T. Wiley, J. S. Lee \& R. Rumberger (Eds.), The education of language minority students in the United States. Clevedon, UK: Multilingual Matters.

LeBlanc, R., \& Painchard, G. (1985). Self-assessment of a second language placement instrument. TESOL Quarterly, 19(4), 673-87.

López, D. (1996). Language: Diversity and assimilation. In R. Waldinger \& M. Bozorgmehr (Eds.), Ethnic Los Angeles (pp. 139-163). New York: Russell Sage Foundation.

Luo, S., \& Wiseman, R. (2000). Ethnic language maintenance among Chinese immigrant children in the United States. International Journal of Intercultural Relations, 24(3), 307-324.

Min, P.G. (Ed.). (2005). Asian Americans: Contemporary trends and issues ( $2^{\text {nd }}$ ed.). Thousand Oaks, CA: Pine Forge Press.

Moll, L., Amanti, C., Neff, D., Gonzalez, N. (1992). Funds of knowledge for teaching: Using a qualitative approach to connect homes and classrooms. Theory into practice, 31(2), 132-141.

Nguyen, A., Shin, F., \& Krashen, S. (2001). Development of the first language is not a barrier to second language acquisition: Evidence from Vietnamese immigrants in the US. International Journal of Bilingual Education and Bilingualism, 4(3), 159-164.

Ogbu, J. U. (1987). Variability in minority school performance: A problem in search of explanation. Anthropology \& Education Quarterly, 18(4), 312-334.

Ogbu J. U., Simons H.D. (1998). Voluntary and involuntary minorities: A CulturalEcological Theory of school performance with some implications for education. Anthropology \& Education Quarterly, 29(2), 155-188. 
Ong, A. (2004). Buddha is hiding: Refugees, citizenship, the new America. Berkeley, CA: University of California Press.

Oscarson, M. (1989). Self-assessment of language proficiency: Rationale and application. Language Testing, 6(1), 1-13.

Oskarsson, M. (1978). Approaches to self-assessment in foreign language learning. London: Pergamon.

Oskarsson, M. (1984). Self-assessment of foreign language skills: A survey of research and development work. Starsbourg: Council of Europe.

Owen, N. G. (Ed.) (2005). The emergence of modern Southeast Asia: A new history. Honolulu: University of Hawaii Press.

Phinney, J., Romero, I., Nava, M., \& Huang, D. (2001). The role of language, parents and peers in ethnic identity among adolescents in immigrant families. Journal of Youth and Adolescence, 30, 135-153.

Portes, A., \& Hao, L. (2002). The price of uniformity: Language, family and personality adjustment in the immigrant second generation. Ethnic and Racial Studies, 25(6), 889-912.

Portes, A., \& Rumbaut, R. G. (2001). The story of the immigrant second generation. Berkeley, CA: University of California Press.

Reeves, T. J., \& Bennett, C. E. (2004). We the people: Asians in the United States, Census 2000 Special Reports. Washington, DC: U.S. Census Bureau.

Rumbaut, R. G. (2004). Ages, life stages, and generational cohorts: Decomposing the immigrant first and second generations in the United States. The International Migration Review, 38(3), 1160-1205.

Rumbaut, R. G., \& Ima, K. (1988). The adaptation of Southeast Asian refugee youth. San Diego, CA: Southeast Asian Refugee Youth Study, Department of Sociology, San Diego State University.

Rumbaut, R. G., \& Portes, A. (2001). Ethnicities: Children of immigrants in America. New York: Russell Sage Foundation.

Shin, S. (2005). Developing in two languages. Clevedon, UK: Multilingual Matters.

Smith-Hefner, N. J. (1990). Language and identity in the education of Boston-area Khmer. Anthropology and Education Quarterly, 24(2), 135-158.

Smith-Hefner, N. J. (1993). Language, gender, and generational conflict among Khmer refugees. Anthropology and Education Quarterly, 21(3), 250-268.

Smith-Hefner, N. J. (1999). Khmer American: Identity and moral education in a diasporic community. Berkeley, CA: University of California Press.

Souryasack, R., \& J. S. Lee (2007). Drawing on students' experiences, cultures and languages to develop English language writing perspectives from three Lao heritage middle school students. Heritage Language Journal, 5(1), 79-97. Retrieved April 28, 2008, from http://www.heritagelanguages.org/

Stalikas, A., \& Gavaki, E. (1995). The importance of ethnic identity: Self-esteem and academic achievement of second-generation Greeks in secondary school. The Canadian Journal of School Psychology, 11(1), 1-9.

Sun, Y. (2001). Family environment and adolescents' well-being before and after parents' martial disruption: A longitudinal analysis. Journal of Marriage and Family, 63(3), 697-713. 
Tang, S. S. (2006). Gangs, schools and what else? Educational challenges, street intervention, and cultural/community development for Khmer American youth in Revere and Lynn, Massachusetts. Washington, DC: Southeast Asia Resource Action Center. Retrieved on June 4, 2008, from http://www.searac.org/3-savepaper2006.pdf

Tannenbaum, M., \& Howie, P. (2002). The association between language maintenance and family relations: Chinese immigrant children in Australia. Journal of Multilingual and Multicultural Development, 23(5), 408-424.

Tse, L. (1998). Affecting affect: The impact of heritage language programs on student attitudes. In S. Krashen, L. Tse, \& J. McQuillan (Eds.), Heritage language development (pp. 51-72). Culver City, CA: Language Education Associates.

Um, K. (1999). Scars of war: Educational issues and challenges for Cambodian-American students. In C. C. Park \& M. M. Chi (Eds.), Asian American Education: Prospects and Challenges (pp. 263-284). Westport, CT: Bergin \& Garvey.

Valdés, G. (2000). Introduction. In N. Anderson (Ed.), AATSP Professional Development Series Handbook for Teachers K-16: Vol 1. Spanish for Native Speakers (pp. 1-20). Orlando, FL: Harcourt College Publishers.

Veltman, C. (1988). Modeling the language shift process of Hispanic immigrants. International Migration Review, 22(4), 545-562.

Willmott, W. E. (1967). The Chinese in Cambodia. Vancouver: University of British Columbia Publications Centre.

Wong Fillmore, L. (2000). Loss of family languages: Should educators be concerned? Theory into Practice, 39(4), 203-210.

Wright, W. E. (2003). The success and demise of a Khmer (Cambodian) bilingual education program: A case study. In C. C. Park, A. L. Goodwin \& S. J. Lee (Eds.), Asian American identities, families, and schooling (pp. 225-252). Greenwich, CT: Information Age Publishing.

Wright, W. E. (2004). What English-only really means: A study of the implementation of California language policy with Cambodian-American students. International Journal of Bilingual Education and Bilingualism, 7(1), 1-23.

Zentella, A. C. (1997). Growing up bilingual: Puerto Rican children in New York. Malden, MA: Blackwell Publishers.

\section{About the Authors}

Ravy S. Lao, a Chinese-Khmer American, is a third year doctoral student at the Gevirtz Graduate School of Education at the University of California, Santa Barbara (UCSB). Her research interests focus on the education of children of immigrants, particularly how their "multiple worlds" influence their academic pathways. Lao's previous studies include a B.A. in English from the University of California, Irvine and an M.A. in TESL/Multicultural Education from Loyola Marymount University. After obtaining her M.A., she taught courses in ESL and writing at the community college and university level in Southern California to students for whom English was their second language. Presently, she serves as a member of the editorial board for Spaces for Difference: An Interdisciplinary Journal, UCSB's graduate student publication, and a member of the doctoral student editorial board for the Journal of Southeast Asian American Education and Advancement. 


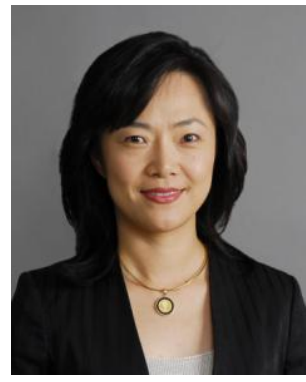

Jin Sook Lee is an assistant professor in the Gevirtz Graduate School of Education at the University of California, Santa Barbara. She received her doctorate in Education from Stanford University. Her research interests focus on the cultural, sociopolitical, and sociopsychological factors that influence the language learning processes of immigrant children. Her current research projects examine the role of heritage language learning in the development of cultural identity and the development of dual language competence among young immigrant children. She serves on the editorial board of the International Multilingual Research Journal and Language Arts and is currently co-editing a book entitled The Education of Language Minority Students in the United States (Multilingual Matters) with Terrence Wiley and Russ Rumberger. She is a recent recipient of the Foundation for Child Development Young Scholars Program Award. 


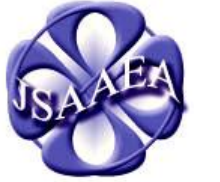

Volume 4 (2009)

\section{Journal of Southeast Asian American Education \& Advancement WwW.JSAAEA.org}

Dr. Wayne E. Wright

University of Texas, San Antonio

Associate Editors

Dr. Chhany Sak-Humphry

University of Hawaii

Dr. KimOanh Nguyen-Lam

California State University, Long Beach

Book Review Editor

Vichet Chhuon

University of California-Santa Barbara

Creative Works Editor

Phouang Hamilton

Washington Office of Superintendent of Public Instruction

\section{Editorial Assistant}

Mariana Kuhl

University of Texas, San Antonio

Comments and questions for the editorial staff may be directed to jsaaea@ lists.sis.utsa.edu

\section{Editorial Review Board}

\author{
Dr. Carl L. Bankston III \\ Tulane University \\ Dr. Phala Chea \\ Lowell Public Schools \\ Dr. Changming Duan \\ University of Missouri, Kansas City \\ Dr. Nancy H. Hornberger \\ University of Pennsylvania \\ Dr. Peter Nien-Chu Kiang \\ University of Massachusetts, Boston \\ Dr. Stacey Lee \\ University of Wisconsin, Madison \\ Dr. Sue Needham \\ California State University, Dominguez Hills
}

A peer-reviewed

scholarly journal published by the

National Association

for the Education \&

Advancement of

Cambodian, Laotian,

and Vietnamese

Americans (NAFEA)

\author{
Dr. Pollie Bith-Melander \\ Asian and Pacific Islander Wellness Center \\ Dr. George Chigas \\ University of Massachusetts, Lowell
}

Dr. Sophal Ear

U.S. Naval Postgraduate School

Dr. Samlong Inthaly

Minneapolis Public Schools

Dr. Kevin K. Kumashiro

University of Illinois, Chicago

Dr. David Chanpannha Ley

Montgomery County Public Schools

Dr. Bic Ngo

University of Wisconsin-Madison 


\author{
Dr. Max Niedzwiecki \\ Daylight Consulting Group \\ Dr. Clara Park \\ California State University, Northridge \\ Dr. Loan T. Phan \\ University of New Hampshire \\ Dr. Karen Quintiliani \\ California State University, Long Beach \\ Dr. Fay Shin \\ California State University, Long Beach \\ Dr. Yer J. Thao \\ Portland State University \\ Dr. Khatharya Um \\ University of California, Berkeley \\ Dr. Terrence G. Wiley \\ Arizona State University \\ Dr. Leakhena Nou \\ California State University, Long Beach \\ Dr. Mark Pfeifer \\ Texas A\&M University, Corpus Christi \\ Dr. Bounlieng Phommasouvanh \\ Minnesota Department of Education \\ Dr. Kalyani Rai \\ University of Wisconsin, Milwaukee \\ Dr. Nancy J. Smith-Hefner \\ Boston University \\ Dr. Myluong Tran \\ San Diego State University \\ Dr. Linda Trinh Vo \\ University of California, Irvine \\ Dr. Zha Blong Xiong \\ University of Minnesota \\ Dr. Kou Yang \\ California State University, Stanislaus

\section{Doctoral Student Editorial Review Board} \\ Keo Chea \\ University of Pennsylvania \\ Loan Dao \\ University of California, Berkeley \\ Ha Lam \\ Arizona State University \\ Monirith Ly \\ Texas State University \\ Rassamichanh Souryasack \\ University of California, Santa Barbara \\ Layheng Ting \\ State University of New York, Albany \\ Ravy Lao \\ University of California, Santa Barbara \\ Vanna Som \\ Harvard University \\ Giang Pham \\ University of Minnesota \\ Tinou Tran \\ University of Houston, Texas \\ Phitsamay Sychitkokhong Uy \\ Harvard University \\ Tinou Tran \\ University of Houston, Texas

\section{Loan Tran} \\ University of California, Santa Barbara
}

